\title{
What might explain deprivation-specific differences in the excess hazard of breast cancer death amongst screen-detected women? Analysis of patients diagnosed in the West Midlands region of England from 1989 to 2011
}

\author{
Melanie Morris ${ }^{1}$, Laura M. Woods ${ }^{1}$, Bernard Rachet ${ }^{1}$ \\ ${ }^{1}$ Cancer Research UK Cancer Survival Group, Faculty of Epidemiology and Population Health, Department of Non-Communicable \\ Disease Epidemiology, London School of Hygiene \& Tropical Medicine, London WC1E 7HT, UK \\ Correspondence to: Melanie Morris, email: melanie.morris@lshtm.ac.uk \\ Keywords: breast cancer, socioeconomic inequalities, survival analysis, early diagnosis, population-based \\ Received: March 17, $2016 \quad$ Accepted: May 23, $2016 \quad$ Published: June 23, 2016
}

\section{ABSTRACT}

Background: Breast cancer survival is higher in less deprived women, even amongst women whose tumor was screen-detected, but reasons behind this have not been comprehensively investigated.

Methods: The excess hazard of breast cancer death in 20,265 women diagnosed with breast cancer, followed up to 2012, was estimated for screen-detected and nonscreen-detected women, comparing more deprived to less deprived women using flexible parametric models. Models were adjusted for individual and tumor factors, treatment received and comorbidity. For screen-detected women, estimates were also corrected for lead-time and overdiagnosis.

Results: The excess hazard ratio (EHR) of breast cancer death in the most deprived group, adjusted only for age and year of diagnosis, was twice that of the least deprived among screen-detected women $(E H R=2.12,95 \% C I 1.48-2.76)$ and $64 \%$ higher among non-screen-detected women (EHR=1.64, 95\%CI 1.411.87). Adjustment for stage at diagnosis lowered these estimates by $25 \%$. Further adjustment had little extra impact. In the final models, the excess hazard for the most deprived women was 54\% higher (EHR $=1.54,95 \% \mathrm{CI} 1.10-1.98)$ among screendetected women and $39 \%$ higher $(E H R=1.39,95 \% C I$ 1.20-1.59) among non-screendetected women.

Conclusion: A persistent socio-economic gradient in breast cancer-related death exists in this cohort, even for screen-detected women. The impact of differential lifestyles, management and treatment warrant further investigation.

\section{INTRODUCTION}

In the UK, deprived women have lower breast cancer survival [1-5]. This has also been found to be the case in other countries [6-9]. The overall difference in breast cancer survival between affluent and deprived women was not modified in the UK by introduction of screening in 1989 [10] and remains despite a mature screening program and a recent narrowing of the survival gap [11]. The discrepancy in survival by deprivation remains a key focus of public health policy [12].

We have previously examined this cohort 20, 265 women diagnosed in the West Midlands region of England from 1989 to 2011 [5]. We reported higher breast cancer survival in less deprived women amongst both women whose cancer was detected following symptoms, as well as amongst women whose tumor was screen-detected, and thus likely to be asymptomatic. In the same analysis, we showed no differences in breast cancer survival between ethnic groups. Together, these findings suggest that, although screening confers a survival benefit to all women, there are still wide, unexplained disparities in breast cancer survival by deprivation.

Whereas socio-economic inequalities overall may partly be explained by later presentation, leading to more advanced disease [13-15] it is less probable that stage of disease explains socio-economic differences amongst screen-detected women who are asymptomatic 
at presentation. Reasons for this residual socio-economic gradient in breast cancer survival in screen-detected women have not yet been comprehensively investigated. Screen-detected women provide an ideal opportunity to examine these since the differences in stage at presentation between more and less deprived women is substantially reduced.

Here we model the excess hazard of breast cancer death (i.e. the hazard of death on top of the expected hazard of death, therefore related to breast cancer) amongst more deprived compared to more affluent women, in order to examine whether variations in tumor characteristics, pre-existing comorbidities or surgery might explain deprivation-specific inequalities in breast cancer survival where women have been diagnosed asymptomatically.

\section{RESULTS}

\section{Cohort characteristics}

We included in the analysis 20,265 women who had a first primary malignant breast tumor (mean age 57.5 years, standard deviation $=5.0,96.4 \%$ of those eligible) and who were continuously eligible for screening from the age of 50 onwards. We compared women whose breast cancer was screen-detected $(\mathrm{n}=10,502,51.8 \%)$ to women who were not screen-detected ( $\mathrm{n}=9,763,48.2 \%)$.

Most women were diagnosed with localized disease $(60.0 \%)$ and were alive at the end of follow-up $(81.6 \%$, Table 1). There were more women in the less deprived categories (e.g. $22.1 \%$ in the least deprived compared with $17.0 \%$ in the most deprived). Women in the more deprived categories were less likely to have local disease $(58.0 \%$ in the most deprived compared to $62.2 \%$ in the least deprived women, $\chi^{2}$ p-value $<0.001$ ) or first surgery within 2 weeks of diagnosis $(31.3 \%$ compared to $37.2 \%, \mathrm{p}<0.001)$ and more likely to have larger tumors $(6.2 \%$ compared to $4.7 \%, \mathrm{p}<0.001)$, comorbidities $(7.3 \%$ compared to $4.0 \%$, $\mathrm{p}<0.001)$ and be deceased by the end of follow-up $(21.8 \%$ compared to $16.2 \%, \mathrm{p}<0.001)$. They were also slightly older (e.g. 11.6\% compared to $9.3 \%$ in the oldest age group, $\mathrm{p}=0.04)$. Grade did not vary across deprivation categories $(p=0.260)$, nor did screening history $(p=0.120)$.

\section{Excess hazard of breast cancer death}

Among non-screen-detected women, the excess hazard of death from breast cancer, adjusted only for age and year of diagnosis, within five years of diagnosis was $64 \%$ higher in the most deprived group compared with the least deprived group $(\mathrm{EHR}=1.64,95 \% \mathrm{CI} 1.41-1.87)$ (Table 2) and more than double among screen-detected women $(\mathrm{EHR}=2.12$, 95\%CI 1.48-2.76). These hazard ratios reduced by around $25 \%$ after adjustment for stage of disease. Tumor characteristics and treatment did not have any notable impact. The inclusion of comorbidity reduced the excess hazard ratios slightly in both groups.
There was a time-varying effect of age in the nonscreen-detected group. Time to surgery did not improve the fit of the final model for the screen-detected group but was included for non-screen-detected women. No interactions were found. In the final models, the excess hazard for women in the most deprived group was 39\% higher $(\mathrm{EHR}=1.39,95 \% \mathrm{CI} 1.20-1.59)$ among non-screendetected women, and 54\% higher $(\mathrm{EHR}=1.54,95 \% \mathrm{CI}$ 1.10-1.98) for the screen-detected.

\section{Sensitivity analysis}

The sensitivity analysis suggested that use of the complete case data underestimated the excess hazard which was adjusted only for age and year of diagnosis, (by $5 \%$ in non-screen-detected and $8 \%$ in screen-detected). The analysis also showed that results for the final model were likely to be robust; when all the less deprived women had favorable tumors and all the more deprived had unfavorable, excess mortality remained higher for deprived women, by $19 \%$ in non-screen-detected and $49 \%$ in screen-detected women (Table 3).

\section{DISCUSSION}

We have demonstrated a socio-economic gradient in breast cancer-related death in the West Midlands among women eligible for screening regardless of whether the woman's breast cancer was screen-detected or not. This difference persists after adjustment for stage of disease at diagnosis (including size of tumor), histology, surgery (including time to surgery) and preexisting comorbidities.

The data used for this study come from a center of excellence, individually linked for each woman to various data sources with good completeness on most variables. Uniquely and importantly, our cohort for analysis included only women aged 50 to 70 years old who had been continuously eligible for screening, in order to exclude women diagnosed within the screening age range but who had no opportunity for the cancer to be screen-detected at the time of diagnosis.

We used robust, up-to-date statistical techniques to estimate the differences in the excess hazard of cancer death between more affluent and more deprived women. We used deprivation- and ethnicity-adjusted life tables in order to obtain the most accurate correction for background mortality [16, 17]. We also corrected for lead time bias [18, 19] and overdiagnosis, which allowed a direct comparison between screen-detected and non-screen-detected women [20, 21]. Studies in other countries have looked at the impact of screening and socio-economic status on breast cancer survival, and come to similar conclusions to this study $[7,8,22]$. However, none have used the net survival framework (either net survival or the excess hazard of breast cancer death), nor 
adjusted for lead-time or overdiagnosis as we do here. As such, they may have overestimated the difference between deprivation groups. In addition, none of these previous studies has taken place in England and thus they have not examined the particular context of the NHS Breast Screening Programme.

Table 1: Cohort and tumor characteristics by deprivation category, $n(\%)$ and mean [standard deviation] for continuous variables

\begin{tabular}{|c|c|c|c|c|c|c|c|}
\hline $\mathrm{N}=\mathbf{2 0 , 2 6 5}$ & $\begin{array}{c}\text { Least deprived } \\
1\end{array}$ & 2 & 3 & 4 & $\begin{array}{c}\text { Most deprived } \\
5\end{array}$ & Total & $\begin{array}{c}\text { p-value } \\
\left(\chi^{2}\right)\end{array}$ \\
\hline \multicolumn{8}{|c|}{ Age at diagnosis ${ }^{\mathrm{a}}$} \\
\hline Mean [sd] & $57.2[4.9]$ & $57.6[5.1]$ & $57.5[5.0]$ & $57.5[5.1]$ & $57.7[5.1]$ & $57.5[5.0]$ & \multirow{5}{*}{0.040} \\
\hline $50-54$ & $1,576(35.2)$ & $1,556(33.7)$ & $1,407(33.7)$ & $1,218(34.3)$ & $1,122(32.5)$ & $6,879(33.9)$ & \\
\hline 55-59 & $1,442(32.2)$ & $1,412(30.6)$ & $1,307(31.3)$ & $1,084(30.6)$ & $1,089(31.6)$ & $6,334(31.3)$ & \\
\hline $60-64$ & $1,042(23.3)$ & $1,141(24.7)$ & $990(23.7)$ & $847(23.9)$ & $840(24.3)$ & $4,860(24.0)$ & \\
\hline $65-70$ & $418(9.3)$ & $505(10.9)$ & $472(11.3)$ & $397(11.2)$ & $400(11.6)$ & $2,192(10.8)$ & \\
\hline \multicolumn{8}{|c|}{ Vital status at end of follow up } \\
\hline Alive & $3752(83.8)$ & $3854(83.5)$ & $3421(81.9)$ & $2810(79.2)$ & $2699(78.2)$ & $16,536(81.6)$ & \multirow{2}{*}{$<0.001$} \\
\hline Dead & $726(16.2)$ & $760(16.5)$ & $755(18.1)$ & $736(20.8)$ & $752(21.8)$ & $3,729(18.4)$ & \\
\hline \multicolumn{8}{|c|}{ Screening history ${ }^{b}$} \\
\hline SD & $2,320(51.8)$ & $2,380(51.6)$ & $2,232(53.4)$ & $1,830(51.6)$ & $1,740(50.4)$ & $10,502(51.8)$ & \multirow{2}{*}{0.120} \\
\hline Not SD & $2,158(48.2)$ & $2,234(48.4)$ & $1,944(46.6)$ & $1,716(48.4)$ & $1,711(49.6)$ & $9,763(48.2)$ & \\
\hline \multicolumn{8}{|c|}{ Period of diagnosis ${ }^{a}$} \\
\hline 1989-1994 & $200(4.5)$ & $167(3.6)$ & $161(3.9)$ & $136(3.8)$ & $137(4.0)$ & $801(4.0)$ & \multirow{4}{*}{$<0.001$} \\
\hline 1995-2000 & 934 (20.9) & $866(18.8)$ & $787(18.8)$ & $651(18.4)$ & $600(17.4)$ & $3,838(18.9)$ & \\
\hline 2001-2006 & $1,765(39.4)$ & $1,781(38.6)$ & $1,555(37.2)$ & $1,383(39.0)$ & $1,300(37.7)$ & 7,784 (38.4) & \\
\hline 2007-2011 & $1,579(35.3)$ & $1,800(39.0)$ & $1,673(40.1)$ & $1,376(38.8)$ & $1,414(41.0)$ & $7,842(38.7)$ & \\
\hline \multicolumn{8}{|c|}{ Extent of disease } \\
\hline Local & $2,786(62.2)$ & $2,795(60.6)$ & $2,539(60.8)$ & $2,048(57.8)$ & $2,002(58.0)$ & $12,170(60.1)$ & \multirow{4}{*}{$<0.001$} \\
\hline Regional & $1,305(29.1)$ & $1,435(31.1)$ & $1,303(31.2)$ & $1,169(33.0)$ & $1,146(33.2)$ & $6,358(31.4)$ & \\
\hline Distant & $98(2.2)$ & $97(2.1)$ & $78(1.9)$ & $106(3.0)$ & $104(3.0)$ & $483(2.4)$ & \\
\hline Missing & $289(6.5)$ & $287(6.2)$ & $256(6.1)$ & $223(6.3)$ & $199(5.8)$ & $1,254(6.2)$ & \\
\hline \multicolumn{8}{|c|}{ Histological group } \\
\hline Ductal & $3,274(73.1)$ & $3,297(71.5)$ & $2,962(70.9)$ & $2,475(69.8)$ & $2,497(72.4)$ & 14,505 (71.6) & \multirow{4}{*}{0.001} \\
\hline Lobular & $673(15.0)$ & $784(17.0)$ & $690(16.5)$ & $581(16.4)$ & $486(14.1)$ & $3,214(15.9)$ & \\
\hline All other & $509(11.4)$ & $512(11.1)$ & $503(12.0)$ & $463(13.1)$ & $442(12.8)$ & $2,429(12.0)$ & \\
\hline Missing & $22(0.5)$ & $21(0.5)$ & $21(0.5)$ & $27(0.8)$ & $26(0.8)$ & $117(0.6)$ & \\
\hline \multicolumn{8}{|c|}{ Grade of tumor } \\
\hline I & $932(20.8)$ & $932(20.2)$ & $858(20.5)$ & $692(19.5)$ & $671(19.4)$ & $4,085(20.2)$ & \multirow{4}{*}{0.260} \\
\hline II & $1,897(42.4)$ & $2,027(43.9)$ & $1,778(42.6)$ & $1,537(43.3)$ & $1,436(41.6)$ & $8,675(42.8)$ & \\
\hline III & $1,292(28.9)$ & $1,286(27.9)$ & $1,222(29.3)$ & $1,019(28.7)$ & $1,072(31.1)$ & $5,891(29.1)$ & \\
\hline Missing & 357 (8.0) & $369(8.0)$ & $318(7.6)$ & $298(8.4)$ & $272(7.9)$ & $1,614(8.0)$ & \\
\hline
\end{tabular}

(Continued) 


\begin{tabular}{|c|c|c|c|c|c|c|c|}
\hline $\mathrm{N}=\mathbf{2 0 , 2 6 5}$ & $\begin{array}{c}\text { Least deprived } \\
1\end{array}$ & 2 & 3 & 4 & $\begin{array}{c}\text { Most deprived } \\
5 \\
\end{array}$ & Total & $\begin{array}{c}\text { p-value } \\
\left(\chi^{2}\right)\end{array}$ \\
\hline \multicolumn{8}{|c|}{ Size of tumor $(\mathrm{mm})^{\mathrm{a}, \mathrm{c}}$} \\
\hline Mean [sd] & $20.1[15.4]$ & $20.5[15.7]$ & $21.1[17.5]$ & $21.4[17.1]$ & $22.4[17.4]$ & $21.0[16.6]$ & \multirow{5}{*}{$<0.001$} \\
\hline $0-20$ & $2,490(55.6)$ & $2,486(53.9)$ & $2,242(53.7)$ & $1,839(51.9)$ & $1,707(49.5)$ & $10,764(53.1)$ & \\
\hline $20-50$ & $1,380(30.8)$ & $1,484(32.2)$ & $1,387(33.2)$ & $1,183(33.4)$ & $1,251(36.3)$ & 6,685 (33.0) & \\
\hline 50 mm+ & $211(4.7)$ & $237(5.1)$ & $226(5.4)$ & $199(5.6)$ & $215(6.2)$ & $1,088(5.4)$ & \\
\hline Missing & $397(8.9)$ & $407(8.8)$ & $321(7.7)$ & $325(9.2)$ & $278(8.1)$ & $1,728(8.5)$ & \\
\hline \multicolumn{8}{|l|}{ Charlson score } \\
\hline $\mathbf{0}$ & 4,301 (96.0) & $4,444(96.3)$ & 3,991 (95.6) & $3,345(94.3)$ & $3,199(92.7)$ & $19,280(95.1)$ & \multirow{4}{*}{$<0.001$} \\
\hline 1 & $77(1.7)$ & $90(2.0)$ & $99(2.4)$ & $100(2.8)$ & $151(4.4)$ & $517(2.6)$ & \\
\hline 2 & $92(2.1)$ & $71(1.5)$ & $68(1.6)$ & $84(2.4)$ & $77(2.2)$ & $392(1.9)$ & \\
\hline 3 & $8(0.2)$ & $9(0.2)$ & $18(0.4)$ & $17(0.5)$ & $24(0.7)$ & $76(0.4)$ & \\
\hline \multicolumn{8}{|l|}{ Surgery } \\
\hline No & $288(6.4)$ & $306(6.6)$ & $252(6.0)$ & $289(8.2)$ & $279(8.1)$ & $1,414(7.0)$ & \multirow{3}{*}{$<0.001$} \\
\hline Yes & $4,190(93.6)$ & $4,308(93.4)$ & $3,924(94.0)$ & $3,257(91.8)$ & $3,172(91.9)$ & $18,851(93.0)$ & \\
\hline Total & $4,478(100)$ & $4,614(100)$ & $4,176(100)$ & $3,546(100)$ & $3,451(100)$ & $20,265(100)$ & \\
\hline \multicolumn{8}{|c|}{ Time from diagnosis to first surgery ${ }^{\text {a }}$ among those who had surgery, $n=18,851$ ) } \\
\hline $\begin{array}{l}\text { Mean [sd] } \\
\text { (days) }\end{array}$ & $21.6[23.6]$ & $22.6[24.9]$ & $22.1[23.4]$ & $23.5[25.5]$ & $23.5[25.2]$ & $22.6[24.5]$ & \multirow{6}{*}{$<0.001$} \\
\hline 0 - 2 weeks & $1,557(37.2)$ & $1,530(35.5)$ & $1,313(33.5)$ & $1,036(31.8)$ & $992(31.3)$ & $6,428(34.1)$ & \\
\hline 2 - 6 weeks & $2,317(55.3)$ & $2,408(55.9)$ & $2,336(59.5)$ & $1,934(59.4)$ & $1,914(60.3)$ & $10,909(57.9)$ & \\
\hline $6+$ weeks & $289(6.9)$ & $341(7.9)$ & $250(6.4)$ & $270(8.3)$ & $248(7.8)$ & $1,398(7.4)$ & \\
\hline Missing & $27(0.6)$ & $29(0.7)$ & $25(0.6)$ & $17(0.5)$ & $18(0.6)$ & $116(0.6)$ & \\
\hline Total & $4,190(100)$ & 4,308 (100) & 3,924 (100) & $3,257(100)$ & $3,172(100)$ & $18,851(100)$ & \\
\hline
\end{tabular}

a Fitted as a continuous variable in the model

b $\mathrm{SD}=$ screen detected, not $\mathrm{SD}=$ not screen-detected

${ }^{c}$ Grouped here according to TNM criteria: T1 $>=20 \mathrm{~mm}, \mathrm{~T} 220 \mathrm{~mm}-50 \mathrm{~mm}, \mathrm{~T} 3>=50 \mathrm{~mm}$ [45].

Information on individual deprivation status is unobtainable from any of the data sources available. We thus defined deprivation ecologically using the validated score temporally closest to the women's date of diagnosis, in order to measure as closely as possible the impact of deprivation on diagnosis and cancer management. These ecological data provide only a proxy measure of the underlying variable of interest. They are susceptible to the ecological fallacy, as well as to temporal change. In reality it is probable that these ecologically-based analyses underestimate the true underlying differences between women of different socio-economic status. This could be examined in a dataset where both ecological and individual measures of deprivation could be derived.

We examined the potential impact of missing data upon our results via a sensitivity analysis. This suggests that the differences we observe in the excess hazard of breast cancer death are robust to the (unknown) distributions of missing data. In reality, we consider it probable that the true (unmeasurable) excess hazard ratio falls between the complete-case and sensitivity estimate.

We determined cancer stage using both extent of disease and tumor size at diagnosis. Together these variables resulted in a sizeable reduction in excess mortality estimates for both screened and non-screendetected women. Although extent of disease was strongly associated with deprivation in both screening groups in this study, the proportion of regional and advanced tumors was particularly high in the most deprived category of screen-detected women. These women also had tumors that were larger. This raises the possibility that the more deprived women with symptoms may use screening as an entry point more frequently than the less deprived women with symptoms; that is, attend 'routine' screening when 
Table 2: Screening-specific excess hazard ratios at five years after diagnosis for each model in turn, comparing the most deprived to the least deprived group (reference)

\begin{tabular}{|c|c|c|c|c|c|c|}
\hline \multirow[t]{2}{*}{ Model } & & \multirow[t]{2}{*}{ Variable } & \multicolumn{2}{|c|}{$\begin{array}{c}\text { Form of variable in the } \\
\text { model }\end{array}$} & \multicolumn{2}{|c|}{$\begin{array}{c}\text { Excess Hazard Ratios } \\
(95 \% \text { CIs })\end{array}$} \\
\hline & & & $\begin{array}{l}\text { Non-screen- } \\
\text { detected }\end{array}$ & $\begin{array}{l}\text { Screen- } \\
\text { detected }\end{array}$ & $\begin{array}{c}\text { Non-screen-detected } \\
(n=8,962)\end{array}$ & $\begin{array}{l}\text { Screen-detected } \\
\quad\left(\mathrm{n}=\mathbf{8 , 5 4 1 . 5 ) ^ { \mathrm { a } }}\right.\end{array}$ \\
\hline \multirow[t]{3}{*}{1} & \multirow[t]{3}{*}{$\begin{array}{l}=\text { Baseline ( } 3 \mathrm{df} \\
\text { for baseline } \\
\text { hazard) }\end{array}$} & Age (continuous) & $\begin{array}{c}\text { Non-linear }(2 \mathrm{df}) ; \\
\text { time- varying } \\
\text { effect }(1 \mathrm{df})\end{array}$ & Linear & $1.64(1.41-1.87)$ & $2.12(1.48-2.76)$ \\
\hline & & $\begin{array}{l}\text { Year of diagnosis } \\
\text { (continuous) }\end{array}$ & Linear & Linear & & \\
\hline & & Deprivation (categorical) & Linear & Linear & & \\
\hline \multirow[t]{2}{*}{2} & \multirow{2}{*}{$\begin{array}{l}=1+\text { stage } \\
\text { of disease at } \\
\text { diagnosis }\end{array}$} & $\begin{array}{l}\text { Extent of disease } \\
\text { (categorical) }\end{array}$ & Linear & Linear & $1.47(1.26-1.68)$ & $1.66(1.18-2.13)$ \\
\hline & & Tumor size (continuous) & Linear & Linear & & \\
\hline 3 & $\begin{array}{l}=2+\text { tumor } \\
\text { characteristics }\end{array}$ & Histology (categorical) & Linear & Linear & $1.45(1.24-1.65)$ & $1.65(1.18-2.12)$ \\
\hline \multirow[t]{2}{*}{4} & \multirow[t]{2}{*}{$=3+$ treatment } & Surgery (categorical) & Linear & Linear & $1.44(1.25-1.64)$ & $1.66(1.19-2.13)$ \\
\hline & & $\begin{array}{l}\text { Time to surgery } \\
\text { (continuous) }\end{array}$ & Linear & $\begin{array}{l}\text { Not } \\
\text { included }\end{array}$ & & \\
\hline $\begin{array}{l}\text { Final } \\
\text { model }\end{array}$ & $\begin{array}{l}=4+ \\
\text { Comorbidity }\end{array}$ & $\begin{array}{l}\text { Charlson score } \\
\text { (continuous) }\end{array}$ & Linear & Linear & $1.39(1.20-1.59)$ & $1.54(1.10-1.98)$ \\
\hline
\end{tabular}

aThe number of women in the screen-detected group is the mean of the 10 imputed datasets and excludes women considered to be overdiagnosed.

Table 3: Sensitivity analysis of screening-specific excess hazard ratios at five years after diagnosis, comparing the most deprived to the least deprived group (reference)

\begin{tabular}{|c|c|c|c|c|}
\hline & \multicolumn{2}{|c|}{ Non-screen-detected } & \multicolumn{2}{|c|}{ Screen-detected } \\
\hline & Baseline model & Final model & Baseline model & Final model \\
\hline \multirow[t]{2}{*}{ Complete case } & \multicolumn{2}{|c|}{$n=8,962$} & \multicolumn{2}{|c|}{$\mathrm{n}=8,541.5^{\mathrm{a}}$} \\
\hline & $1.64(1.41-1.87)$ & $1.39(1.20-1.59)$ & $2.12(1.48-2.76)$ & $1.54(1.10-1.98)$ \\
\hline \multirow[t]{2}{*}{ Sensitivity analysis ${ }^{b}$} & \multicolumn{2}{|c|}{$n=9,624$} & \multicolumn{2}{|c|}{$\mathrm{n}=9012.9^{\mathrm{a}}$} \\
\hline & $1.69(1.46-1.92)$ & $1.19(1.03-1.35)$ & $2.20(1.55-2.84)$ & $1.49(1.06-1.91)$ \\
\hline
\end{tabular}

a The number of women in the screen-detected group is the mean of the 10 imputed datasets and excludes women considered to be overdiagnosed.

${ }^{\mathrm{b}}$ Less deprived women with missing data assumed to have small, localized tumors whilst more deprived women with missing data are assumed to have large tumors with distant spread.

they suspect cancer or are experiencing breast symptoms, in place of visiting their GP. Qualitative studies could explore this hypothesis further by examining women's motivations for attending screening by deprivation. Detailed examination of screening attendance patterns amongst all women could also be conducted, for example, examining the proportion of appointments attended on time, late, or not at all amongst more affluent compared to more deprived groups. Additionally, symptom awareness may be lower among the more deprived women [23, 24], leading to more women with regional or distant disease being diagnosed via the screening service. Either way, our data suggest that stage of disease, and thus timeliness of presentation, play a role in deprivation-specific differences 
in the excess hazard, even among screen-detected women, but that important deprivation differences still remain.

We were unable to adjust for other tumor factors including hormone receptor status as these variables were too incomplete. Surprisingly, surgical treatment received did not further explain differences in the excess hazard in either group, where previously this has been shown to be influential [8]. Additionally, time to surgery was not found here to improve the fit of any of the models for the screendetected group, similar to the findings of a recent smaller study [25]. However, the measure available was not very discriminatory, partly because almost all women had surgery, but also because information on hormone therapy, chemotherapy and radiotherapy were too incomplete to use. Administration of neo-adjuvant hormone therapy, not detectable in our data, might also have extended time to surgery for some women.

Comorbidities reduced the deprivation gap in the excess hazard by only a small amount, consistent with the fact that the cohort were ostensibly healthy younger women up to age 70. The impact of comorbidities upon socio-economic differences may be greater among older women $[6,8]$.

Our results suggest that factors other than stage of disease, tumor characteristics, surgical treatment and comorbidity lead to socio-economic differences in the excess hazard of breast cancer death, and that early, asymptomatic diagnosis via screening does not eliminate them. Differential use or receipt of treatments in breast cancer must be considered as an important potential explanation for this, and have previously been shown to be associated with socio-economic differences in survival $[14,15,26-28]$. It has been comprehensively shown that where treatment is consistent (within clinical teams or within clinical trials) socio-economic differences are not apparent [29, 30]. Differences in treatment actually received might originate from differences in ease of travel to appointments, flexibility of work, other commitments or levels of social support [31-33]. Differences in nutrition, smoking, alcohol consumption or other health-related behaviors are also possible explanations, although evidence for the impact of these upon cancer survival differentials is mixed [14]. The possibility of more frequent use of the screening service by more deprived women as a point of entry also deserves further examination.

Deprivation status is the socio-demographic characteristic that most strongly impacts the survival of women in the UK with breast cancer, after age at diagnosis. In this study, we have shown that the more deprived women with breast cancer have a higher excess hazard of cancer death, irrespective of whether their cancer was screen-detected or not. Our data suggest that this pattern is not simply a product of differences in timely diagnosis as it occurs even among women diagnosed asymptomatically. Having accounted here for some patient and tumor factors, we have shown that early diagnosis through screening is not enough to eliminate inequalities, and that the influence of differential cancer management, treatment, as well as lifestyles or life challenges of breast cancer patients from more deprived communities warrants further investigation.

\section{MATERIALS AND METHODS}

\section{Data}

As in our previous study, [5] the cohort consisted of women diagnosed with a primary, invasive breast cancer during the period 1 April 1989-31 March 2011, aged 5070 years at their diagnosis, who were continuously eligible for screening from the age of 50 up to either 65 or 70 years (if the screening service expanded) and who would have received their first invitation letter from their 50th birthday onwards. A total of 20,283 women were included after excluding 761 women (3.6\% of those eligible). These exclusions mainly comprised women whose tumors were recurrences of earlier malignancies. The mean date of diagnosis of these women was $14^{\text {th }}$ August 2004. Cancerrelated information on these individuals was obtained from the West Midlands Breast Screening Quality Assurance Reference Centre (Cancer Registry) [34, 35]. These data were individually linked to Hospital Episode Statistics and the National Breast Screening Service records. The vital status of all women was known at the close of follow-up on 31 July 2012, after which each woman's follow-up time was censored. The median follow-up time for all women was 5.77 years. For the 3,732 women who died during the study period median follow-up was 3.24 years.

Women whose breast cancer was not screen-detected included those whose last screening attendance had resulted in a negative screen and had not yet been invited to a subsequent screening (interval cancer; $\mathrm{n}=6,311$, $31.1 \%$ ); women whose cancer was diagnosed after having previously had a negative screen, but who had not attended their most recent screening appointment (lapsed attenders, $\mathrm{n}=1,142,5.6 \%$ ); and women who had never presented for screening (non-attenders, $\mathrm{n}=2,310,11.4 \%$ ).

Deprivation was measured using the income domain of the English indices of multiple deprivation (IMD) for 2004, 2007 or 2010 [36-38]. These ecologically-based scores are derived from routine administrative data pertaining to the years 2001, 2005 and 2008 respectively, and are calculated for each of the 32,482 Lower Super Output Areas as defined at the 2001 census (LSOAs, approximately 1,500 people). The scores are categorized according to the quintiles of their national distribution. Each woman was assigned to one of five deprivation levels on the basis of her address of residence and date of diagnosis. Those with missing information on deprivation were excluded from all analyses (18 women, 0.1\%), resulting in 20,265 women in the analyses. 
Information on tumor size, nodal involvement and presence of metastases was used to establish each woman's extent of disease at diagnosis, either localized (confined to the organ of origin), regional (spread to adjacent muscle, organ, fat, connective tissue or regional lymph nodes) or distant (distant metastases). Tumors were further categorized by their histology (ductal, lobular or all others) and grade (I, II or III).

Treatment was evaluated by surgery on the tumor within 6 months of diagnosis (yes/no), and time from diagnosis to first surgery. Information on radiology, chemotherapy and hormone therapy was too incomplete to be used $(22.9 \%, 62.5 \%$ and $50.6 \%$ missing respectively).

\section{Adjustment for lead time bias and over-diagnosis}

Lead time bias arises from the inflation of an individual woman's recorded survival due to the cancer being detected at an earlier point in time at screening, but with no associated improvement in prognosis. To account for this we applied the method established by Duffy et al [20]. Our approach has been described previously [5]. Briefly, for each patient, additional survival time due to screening, E(s), was estimated assuming an exponential distribution of survival times, and a mean sojourn time (from carcinogenesis to symptomatic detection) of 4 years. In order to account for the uncertainty associated with this value, we generated 10 separate data sets for the screendetected group containing $\mathrm{E}(\mathrm{s})_{1}, \mathrm{E}(\mathrm{s})_{2} \ldots \mathrm{E}(\mathrm{s})_{10}$ assuming these values were exponentially distributed with a mean of $\mathrm{E}(\mathrm{s})$.

Tumors are considered over-diagnosed if they would not have been detected symptomatically during the study period or during the woman's predicted lifetime [39]. To account for overdiagnosis we excluded tumor records where the value of E(s) exceeded the woman's actual observed survival time, was after 31st March 2011, or in excess of her life expectation at diagnosis (as defined in the life tables).

\section{Modelling of excess hazard ratio}

We fitted flexible parametric log-cumulative excess hazard regression models [40] to estimate the excess hazard ratio which compares the excess hazard of breast cancer death (the analog of net survival) in less deprived women to that in more deprived women during the first five years after diagnosis. The excess hazard is the hazard of death experienced by the cancer patients on top of their expected hazard of death. We used ethnicspecific life tables for England and Wales adjusted for deprivation [41] to estimate expected mortality. Initial models were fitted separately for non-screen detected women, and for the 10 separate datasets derived for screen-detected women. These models included, a priori, age, year of diagnosis and deprivation category.
We tested the linearity of age, year of diagnosis and deprivation category using Akaike's Information Criterion (AIC). A reduction of 3 or more in the AIC between successive models was taken to show a better model fit [42]. We evaluated the time-varying effect of each variable by the inclusion of restricted cubic splines. We subsequently adjusted for the stage of the tumor (using the variables extent of disease and tumor size, including the time-varying effect of extent), tumor characteristics (using histological group), treatment (using surgery and time from diagnosis to first surgery) and the presence of comorbidity (using the Charlson score [43]). Size of tumor and time from diagnosis to first surgery were transformed prior to inclusion in the models. Grade of tumor was excluded since there was no evident association with deprivation (Table 1). We evaluated interactions between age and deprivation, extent of disease and deprivation, and period of diagnosis and deprivation.

This process resulted in one model final specification for the non-screen-detected group and 10 different specifications for the screen-detected group. Eight out of these 10 were identical and thus defined the final specification (Appendix A).

We derived final estimates of the excess hazard ratio in the most deprived compared to the least deprived women using the final specifications. For the screendetected group, the final model specification was fitted to each of the 10 sets of data. We then applied the rules established by Rubin [44] for the re-combination of estimates in a multiple-imputation setting to derive an overall estimate of the hazard ratio and its variance in the screen-detected group, adjusted for lead time bias and over-diagnosis (Appendix B).

\section{Sensitivity analyses for missing data}

The initial models were derived using cases with complete records for all variables $(93.1 \%$ among the nonscreen-detected, 94.8\% among the screen detected). We conducted a sensitivity analysis to examine the possible impact of these missing data on our estimates. Where a variable of interest had more than $1 \%$ missing data (extent of disease, tumor size; Table 1) we imputed values which assumed that the less deprived women with missing data had tumors with much better prognosis. Specifically, values for extent of disease for the less deprived women (categories 1 and 2) were imputed as localized and tumor size to the mean size of localized tumors $(16.6 \mathrm{~mm})$, whilst among the more deprived women (categories 3, 4 and 5) extent of disease was imputed as distant and tumor size to the mean size of distant tumors $(47.8 \mathrm{~mm})$. Variables with less than $1 \%$ of missing data (histology and time to first surgery) were not considered and women with missing information for these variables were excluded from the analyses $(0.6 \%$ and $0.4 \%$ respectively). 


\section{ACKNOWLEDGMENTS}

We would like to gratefully acknowledge Emma O'Sullivan and Nicola Rogers for their assistance in accessing the data, and Christopher Lawrence and Jackie Charman for their help with retrieving and collating the data, all at the West Midlands Breast Screening Quality Assurance Reference Centre. Also, Gill Lawrence, ex-Director of the West Midlands Cancer Intelligence Unit, for her helpful suggestions and guidance.

\section{CONFLICTS OF INTEREST}

None declared.

\section{FUNDING SOURCE}

This work was supported by the National Awareness and Early Diagnosis Initiative (NAEDI) [C23409/A14031 to MM] and by Cancer Research UK [C23409/A11415 to LW and C1336/A11700 to BR].

\section{REFERENCES}

1. Coleman MP, Babb P, Damiecki P, Grosclaude PC, Honjo S, Jones J, Knerer G, Pitard A, Quinn MJ, Sloggett A and De Stavola BL. (1999). Cancer survival trends in England and Wales 1971-1995: deprivation and NHS Region (Studies on Medical and Population Subjects No. 61). (London: The Stationery Office), pp. 55-106.

2. Quinn MJ, Cooper N, Rachet B, Mitry E and Coleman MP. Survival from cancer of the breast in women in England and Wales up to 2001. Br J Cancer. 2008; 99:53-55.

3. Woods LM, Rachet B, O'Connell DL, Lawrence G, Tracey E, Willmore A and Coleman MP. Large differences in patterns of breast cancer survival between Australia and England: a comparative study using cancer registry data. Int J Cancer. 2009; 124:2391-2399.

4. Rachet B, Ellis L, Maringe C, Nur U, Chu T, Quaresma M, Shah A, Walters S, Woods LM, Forman D and Coleman MP. Socioeconomic inequalities in cancer survival in England after the NHS Cancer Plan. Br J Cancer. 2010; 103:446-453.

5. Morris M, Woods LM, Rogers N, O'Sullivan E, Kearins O and Rachet B. Ethnicity, deprivation and screening: survival from breast cancer among screening-eligible women in the West Midlands diagnosed from 1989 to 2011. Br J Cancer. 2015; 113:548-555.

6. Dalton SO, Ross L, During M, Carlsen K, Mortensen PB, Lynch $\mathrm{J}$ and Johansen $\mathrm{C}$. Influence of socioeconomic factors on survival after breast cancer--a nationwide cohort study of women diagnosed with breast cancer in Denmark 19831999. Int J Cancer. 2007; 121:2524-2531.
7. Gentil-Brevet J, Colonna M, Danzon A, Grosclaude P, Chaplain G, Velten M, Bonnetain F and Arveux P. The influence of socio-economic and surveillance characteristics on breast cancer survival: a French population-based study. Br J Cancer. 2008; 98:217-224.

8. Aarts MJ, Voogd AC, Duijm LEM, Coebergh JWW and Louwman WJ. Socioeconomic inequalities in attending the mass screening for breast cancer in the south of the Netherlands-associations with stage at diagnosis and survival. Breast Cancer Res Treat. 2011; 128:517-525.

9. Bastiaannet E, de Craen AJM, Kuppen PJK, Aarts MJ, van der Geest LGM, van de Velde CJH, Westendorp RGJ and Liefers GJ. Socioeconomic differences in survival among breast cancer patients in the Netherlands not explained by tumor size. Breast Cancer Res Treat. 2011; 127:721-727.

10. Coleman MP, Rachet B, Woods LM, Mitry E, Riga M, Cooper N, Quinn MJ, Brenner H and Estève J. Trends and socio-economic inequalities in cancer survival in England and Wales up to 2001. Br J Cancer. 2004; 90:1367-1373.

11. Lyratzopoulos G, Barbiere JM, Rachet B, Baum M, Thompson MR and Coleman MP. Changes over time in socioeconomic inequalities in breast and rectal cancer survival in England and Wales over a 32-year period (19732004): the potential role of health care. Ann Oncol. 2011; 22:1661-1666.

12. Department of Health. (2007). Cancer Reform Strategy. (London: Department of Health), pp. 1-17.

13. Sant M, Allemani C, Capocaccia R, Hakulinen T, Aareleid T, Coebergh JWW, Coleman MP, Grosclaude PC, MartinezGarcia C, Bell CMJ, Williams EMI, Berrino F and EUROCARE Working Group. Stage at diagnosis is a key explanation of differences in breast cancer survival across Europe. Int J Cancer. 2003; 106:416-422.

14. Woods LM, Rachet B and Coleman MP. Origins of socioeconomic inequalities in cancer survival: a review. Ann Oncol. 2006; 17:5-19.

15. Downing A, Prakash K, Gilthorpe MS, Mikeljevic JS and Forman D. Socioeconomic background in relation to stage at diagnosis, treatment and survival in women with breast cancer. Br J Cancer. 2007; 96:836-840.

16. Dickman PW, Auvinen A, Voutilainen ET and Hakulinen T. Measuring social class differences in cancer patient survival: is it necessary to control for social class differences in general population mortality? A Finnish population-based study. J Epidemiol Comm Hlth. 1998; 52:727-734.

17. Blakely T, Soeberg M, Carter K, Costilla R, Atkinson J and Sarfati D. Bias in relative survival methods when using incorrect life-tables: Lung and bladder cancer by smoking status and ethnicity in New Zealand. Int J Cancer. 2012; 131:E974-E982.

18. Hutchison GB and Shapiro S. Lead Time Gained by Diagnostic Screening for Breast Cancer. J Natl Cancer Inst. 1968; 41:665-681. 
19. Ellis L, Woods LM, Estève J, Eloranta S, Coleman MP and Rachet B. Cancer incidence, survival and mortality: explaining the concepts. Int J Cancer. 2014; 135:1774-1782.

20. Duffy SW, Nagtegaal ID, Wallis M, Cafferty FH, Houssami $\mathrm{N}$, Warwick J, Allgood P, Kearins O, Tappenden N, O'Sullivan E and Lawrence G. Correcting for lead time and length bias in estimating the effect of screen detection on cancer survival. Am J Epidemiol. 2008; 168:98-104.

21. Lawrence G, Wallis M, Allgood P, Nagtegaal ID, Warwick J, Cafferty FH, Houssami N, Kearins O, Tappenden N, O'Sullivan E and Duffy SW. Population estimates of survival in women with screen-detected and symptomatic breast cancer taking account of lead time and length bias. Breast Cancer Res Treat. 2009; 116:179-185.

22. Louwman WJ, van de Poll-Franse LV, Fracheboud J, Roukema JA and Coebergh JWW. Impact of a programme of mass mammography screening for breast cancer on socio-economic variation in survival: a population-based study. Breast Cancer Res Treat. 2007; 105:369-375.

23. Grunfeld EA, Ramirez AJ, Hunter MS and Richards MA. Women's knowledge and beliefs regarding breast cancer. Br J Cancer. 2002; 86:1373-1378.

24. Linsell L, Forbes LJL, Burgess C, Kapari M, Thurnham A and Ramirez AJ. Validation of a measurement tool to assess awareness of breast cancer. Eur J Cancer. 2010; 46:1374-1381.

25. Moriceau G, Bourmaud A, Tinquaut F, Oriol M, Jacquin JP, Fournel P, Magne N and Chauvin F. Social inequalities and cancer: can the European deprivation index predict patients' difficulties in health care access? a pilot study. Oncotarget. 2016; 7:1055-1065. doi: 10.18632/oncotarget.6274.

26. Lyratzopoulos G, Barbiere JM, Greenberg DC, Wright KA and Neal DE. Population-based time trends and socioeconomic variation in use of radiotherapy and radical surgery for prostate cancer in a UK region: continuous survey. Br Med J. 2010; 340:c1928.

27. Warwick J, Will O, Allgood P, Miller R, Duffy S and Greenberg D. Variation in colorectal cancer treatment and survival: a cohort study covering the East Anglia region. Colorectal Dis. 2013; 15:1243-1252.

28. Forrest LF, Adams J, Rubin G and White M. The role of receipt and timeliness of treatment in socioeconomic inequalities in lung cancer survival: population-based, datalinkage study. Thorax. 2015; 70:138-145.

29. Lyratzopoulos G, Sheridan GF, Michie HR, McElduff P and Hobbiss JH. Absence of socioeconomic variation in survival from colorectal cancer in patients receiving surgical treatment in one health district: cohort study. Colorectal Dis. 2004; 6:512-517.

30. Nur U, Rachet B, Parmar MKB, Sydes M, Cooper N, Lepage C, Northover JMA, James R, Coleman MP and Collaborators A. No socioeconomic inequalities in colorectal cancer survival within a randomised clinical trial. Br J Cancer. 2008; 99:1923-1928.

31. Jones AP, Haynes R, Sauerzapf V, Crawford SM, Zhao H and Forman D. Travel time to hospital and treatment for breast, colon, rectum, lung, ovary and prostate cancer. Eur J Cancer. 2008; 44:992-999.

32. Sauerzapf VA, Jones AP, Haynes R, Crawford SM and Forman D. Travel time to radiotherapy and uptake of breast-conserving surgery for early stage cancer in Northern England. Health \& Place. 2008; 14:424-433.

33. Lam J, Cook T, Foster S, Poon R, Milross C and Sundaresan P. Examining Determinants of Radiotherapy Access: Do Cost and Radiotherapy Inconvenience Affect Uptake of Breast-conserving Treatment for Early Breast Cancer? Clin Oncol. 2015; 27:465-471.

34. UK Association of Cancer Registries. (2010). UKACR quality and performance indicators 2009: final.

35. Lawrence G, Kearins O, O’Sullivan E, Tappenden N, Wallis $\mathrm{M}$ and Walton $\mathrm{J}$. The West Midlands breast cancer screening status algorithm - methodology and use as an audit tool. J Med Screen. 2005; 12:179-184.

36. Neighbourhood Renewal Unit. (2004). The English indices of deprivation 2004 (revised). (London: Office for the Deputy Prime Minister).

37. Department for Communities and Local Government. (2008). The English Indices of Deprivation 2007. London.

38. Department for Communities and Local Government. (2011). The English Indices of Deprivation 2010. London.

39. Welch HG and Black WC. Overdiagnosis in Cancer. J Natl Cancer Inst. 2010; 102:605-613.

40. Nelson CP, Lambert PC, Squire IB and Jones DR. Flexible parametric models for relative survival, with application in coronary heart disease. Stat Med. 2007; 26:5486-5498.

41. Morris M, Woods LM and Rachet B. A novel ecological methodology for constructing ethnic-majority life tables in the absence of individual ethnicity information. J Epidemiol Comm Hlth. 2015; 69:361-367.

42. Burnham KP and Anderson DR. (2002). Model selection and multimodel inference: a practical information-theoretic approach (New York: Springer).

43. Charlson ME, Pompei P, Ales KL and MacKenzie CR. A new method of classifying prognostic comorbidity in longitudinal studies: Development and validation. J Chronic Dis. 1987; 40:373-383.

44. Rubin DB. (1987). Multiple imputation for nonresponse in surveys. (New York: John Wiley and Sons).

45. Sobin LH, Gospodarowicz M and Wittekind C. (2009). TNM Classification of Malignant Tumours. (New York: John Wiley \& Sons). 